ఠ

\title{
Prognostic role of urokinase plasminogen activator receptor in gastric and colorectal cancer: a systematic review and meta-analysis
}

This article was published in the following Dove Press journal:

OncoTargets and Therapy

19 June 2015

Number of times this article has been viewed

\section{Hong Guo ${ }^{1,2}$ \\ Chun Ling' \\ Yun-yun $\mathrm{Ma}^{\mathrm{I}}$ \\ Lan-xia Zhou' \\ Li Zhao ${ }^{2}$}

'The First Clinical Medical College, Lanzhou University, Lanzhou, ${ }^{2}$ The First Hospital, Lanzhou University, Lanzhou, People's Republic of China
Correspondence: Li Zhao

The First Hospital of Lanzhou University, No I, Donggang West Road, Lanzhou 730000, Gansu, People's Republic of China

Email gszhaoli66@I63.com
Purpose: Although the urokinase plasminogen activator receptor (uPAR) is expressed in gastric cancer (GC) and colorectal cancer (CRC), its evaluation as a prognostic biomarker remains controversial. In this study, we performed a literature review and meta-analysis to evaluate the association of uPAR expression with the prognosis of patients with GC and CRC.

Method: The PubMed database was searched for material published in English, and data were then extracted and assessed by two reviewers independently. Correlations between uPAR expression and clinicopathological features and overall survival (OS) of patients with GC or CRC were analyzed.

Results: A total of 2,082 patients with GC and CRC from ten studies were included. The results of the meta-analysis showed that the UPAR expression rate in GC and CRC tissues was higher than that in normal tissues (odds ratio $[\mathrm{OR}]=3.385$; 95\% confidence interval $[\mathrm{CI}] 2.605-4.400$; $P=0.000$ ). Our meta-analysis also revealed a significant association between uPAR expression and lymph node metastasis $(\mathrm{OR}=1.366 ; 95 \% \mathrm{CI}=1.086-1.718 ; P=0.008)$ and tumor stage $(\mathrm{OR}=3.076 ; 95 \% \mathrm{CI}=2.330-4.061 ; P=0.000)$. Furthermore, we found that high uPAR expression correlated with poor $\mathrm{OS}(\mathrm{OR}=1.937 ; 95 \% \mathrm{CI}=1.570-2.930 ; P=0.000)$.

Conclusion: The uPAR expression may serve as a novel disease marker in GC and CRC, as well as a therapeutic target.

Keywords: uPAR, gastric cancer, colorectal cancer, meta-analysis

\section{Introduction}

Gastrointestinal cancer, mainly including gastric cancer (GC) and colorectal cancer (CRC), is a major health problem that accounts for a large proportion of all human malignancies; ${ }^{1}$ worldwide, approximately 3.25 million people are diagnosed with the disease each year. ${ }^{2}$ Despite recent advances in the diagnosis and therapy of this disease, most GC and CRC patients present with advanced disease, accompanied by a poor prognosis and a low survival rate. With the development and advancement of comprehensive cancer treatment modalities, the prognosis of patients with GC and CRC has improved. However, long-term survival of these patients remains unsatisfactory. Invasion and metastasis are the most important biological characteristics of malignant tumors and the main cause of death. ${ }^{3}$ The molecular mechanisms involved in invasion and metastasis of gastrointestinal cancer remain unclear. Thus, identifying the biological indicators of invasion and metastasis, especially with regard to the prognosis of GC and CRC, is particularly important.

Urokinase plasminogen activator ( $\mathrm{uPA}$ ) is a serine protease that is first secreted as a proenzyme, and then activated by proteolytic cleavage after binding to its specific cell-surface receptor, urokinase plasminogen activator receptor (uPAR). ${ }^{4}$ In many 
human cancers, uPAR is overexpressed in the tumor-stromal invasive microenvironment. ${ }^{5}$ By regulating and targeting proteolysis at the invading edge of a tumor, uPAR plays a critical role in cancer progression through its interaction with integrins and vitronectin and as a regulator of angiogenesis. ${ }^{6}$ Previous studies have shown that uPAR expression was associated with poor prognosis and survival of patients with malignancies..$^{7-9}$ We reviewed studies in the literature on the relationship between UPAR and gastrointestinal cancer and found inconsistent conclusions. Therefore, we conducted a meta-analysis of all available studies to evaluate the association between $\mathrm{UPAR}$ expression and clinical outcome of patients with GC and CRC.

\section{Materials and methods Publication search}

The PubMed database was searched for material published in English; the latest search was updated on November 20, 2014. The searching strategy consisted of combinations of medical subheadings and keywords, such as "gastric cancer" or "colorectal cancer", and "urokinase plasminogen activator receptor" or "uPAR" or "urokinase plasminogen activator system". All references cited in the original studies or review articles concerning the relevant topic were retrieved to broaden the search for relevant publications. Literature screening was independently performed by two reviewers (Hong Guo and Chun Ling).

\section{Inclusion and exclusion criteria}

For this meta-analysis, publications of studies that met the following criteria were included: 1) inclusion of patients with $\mathrm{GC}$ or $\mathrm{CRC}$; 2) investigation of the relationship between uPAR expression and the clinical outcome of patients; $3)$ primary outcomes of interest with clinicopathological features and prognosis; and 4) detection of uPAR in tissues with $\mathrm{GC}$ or CRC. The following exclusion criteria were used: 1) UPAR detection in patient's blood circulation, effusion, or cerebrospinal fluid; 2) uPAR expression in other gastrointestinal cancers, such as hepatocellular cancer and biliary/ cholangio cancer; 3 ) abstracts and reviews; 4) studies without available or exactable data; 5) articles published in a language other than English; 6) repeated or overlapping publications; and 7) animal experiments or literature reviews.

\section{Data extraction}

Two authors (Yun-yun Ma and Lan-xia Zhou) independently extracted the following from the included studies: name of the first author, publication year of the article, country or area, tumor type (GC or CRC), number of patients, clinicopathological parameters, and outcomes. In addition, the response to chemotherapy according to genotype and the hazard ratios (HRs) for overall survival (OS) and their 95\% confidence intervals (CIs) were collected for statistical analyses. Any discrepancies were resolved through discussion or consultation with a third person (Li Zhao).

\section{Statistical analysis}

A chi-square-based $Q$-test was used to test the assumption of heterogeneity. $P>0.1$ for the $Q$-test suggested a lack of heterogeneity among studies and required the use of the fixed effects model (the Mantel-Haenszel method) to estimate the pooled odds ratio (OR) of each study. Otherwise, the random effects model was used. OS was evaluated by using pooled Cox proportional HRs and 95\% CIs. Statistical analyses were performed using Comprehensive Meta-Analysis software (Version 2.0). $P<0.05$ was considered statistically significant, and all $P$-values were two sided.

\section{Results \\ Characteristics of studies used in meta-analysis}

This meta-analysis adheres to the relevant criteria of the Preferred Reporting Items for Systemic Reviews and MetaAnalyses (PRISMA) statement. ${ }^{10}$ According to the search strategy, we initially retrieved 173 articles. Sixty-five of these were excluded by professional software as duplicate publications. We then carefully read and analyzed the titles and abstracts of the remaining 108 articles, omitting 90 that met our exclusion criteria. After reading the full text of the remaining 18 articles, an additional eight were excluded. Finally, ten studies, ${ }^{11-20}$ encompassing 2,082 patients, were included in our meta-analysis. The results of the search strategy for study selection are summarized in Figure 1. Six of the studies involved GC patients; four involved patients with CRC. The studies mainly used three methods to evaluate UPAR expression in gastrointestinal cancer specimens: immunohistochemistry, tissue micro-arrays, and reverse transcriptase-polymerase chain reaction. The primary patient outcomes were OS and survival rates. Characteristics of the eligible studies are summarized in Table 1.

\section{Correlation of UPAR expression with clinicopathological parameters}

This meta-analysis did not detect heterogeneity among the published reports $(P>0.05)$. The fixed effects model was used to analyze the relationship between $\mathrm{UPAR}$ expression 


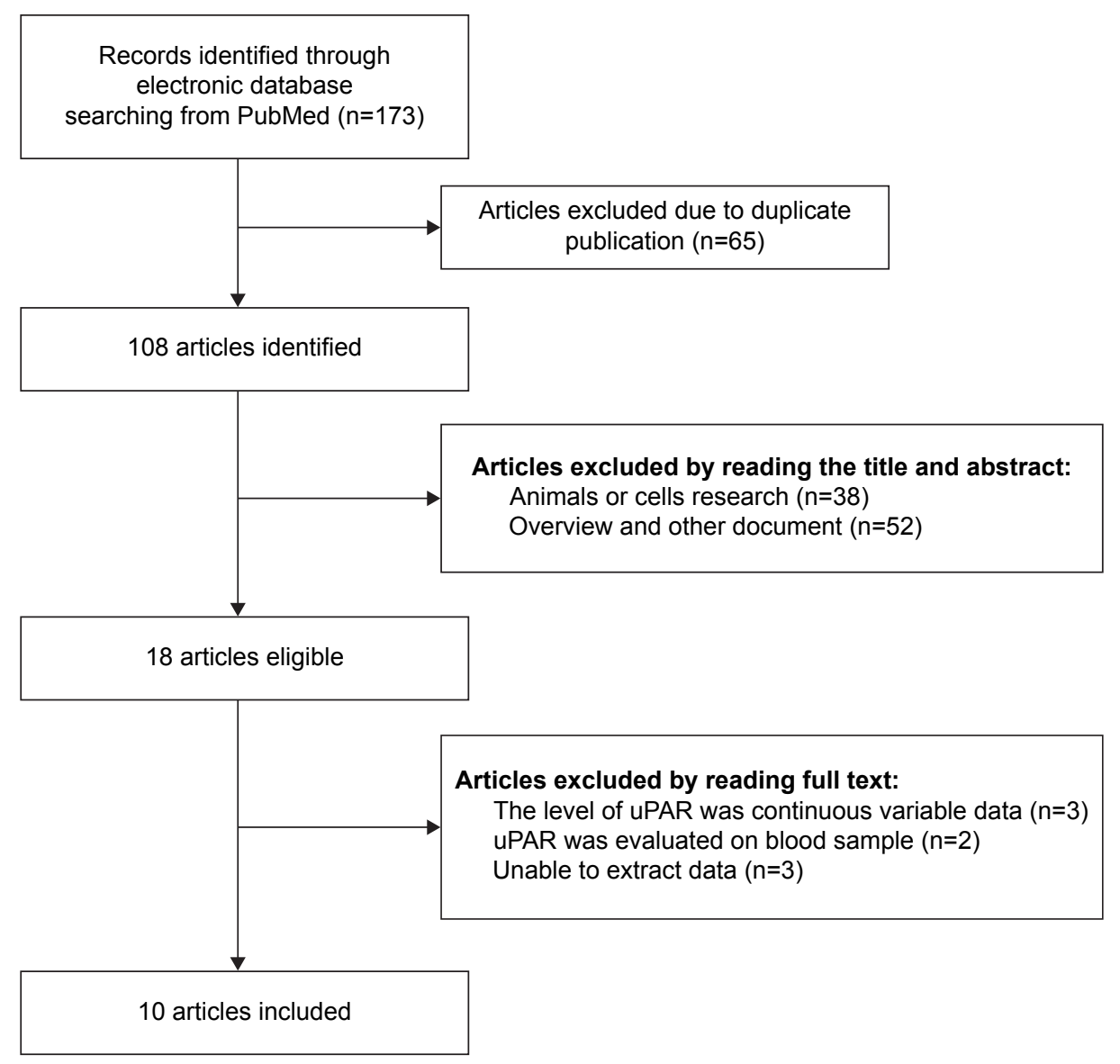

Figure I Flowchart: selection of studies for inclusion in meta-analysis.

Abbreviation: uPAR, urokinase plasminogen activator receptor.

and the clinical characteristics of GC and CRC. Five reports comparing uPAR expression in GC and CRC with that in normal lung tissues showed that the UPAR expression rate in the cancer tissues was higher than that in normal tissues ( $\mathrm{OR}=3.385 ; 95 \% \mathrm{CI}=2.605-4.400 ; P=0.000$ ) (Figure 2). This meta-analysis also revealed a significant association between UPAR expression and lymph node metastasis (OR $=1.366 ; 95 \% \mathrm{CI}=1.086-1.718 ; P=0.008)$ (Figure 3 ). Comparing the uPAR expression in stage I-II and III-IV patients suggested a significant association between positive uPAR expression and tumor stage (OR $=3.076 ; 95 \%$ $\mathrm{CI}=2.330-4.061 ; P=0.000$ ) (Figure 4). Specifically, higher

Table I Characteristics of the eligible studies

\begin{tabular}{|c|c|c|c|c|c|c|c|c|}
\hline Authors & Country & Year & $\mathbf{N}$ & $\begin{array}{l}\text { Tumor } \\
\text { stage }\end{array}$ & $\begin{array}{l}\text { Tumor } \\
\text { types }\end{array}$ & $\begin{array}{l}\text { Measurement } \\
\text { method }\end{array}$ & Cut off & $\begin{array}{l}\text { Survival } \\
\text { analysis }\end{array}$ \\
\hline Alpízar-Alpízar et al"' & Norway & 2012 & 95 & I-IV & GC & $\mathrm{ICH}$ & Score $\geq 1$ & OS \\
\hline Beyer et $\mathrm{al}^{12}$ & Germany & 2006 & 104 & I-IV & GC & $\mathrm{ICH}$ & Score $\geq 1$ & OS \\
\hline Boonstra et $\mathrm{al}^{13}$ & the Netherlands & 2014 & 262 & I-IV & CRC & TMA & Score $\geq 50 \%$ & DFS, OS \\
\hline Kaneko et al ${ }^{14}$ & Japan & 2003 & 101 & - & GC & $\mathrm{ICH}$ & Score $\geq 50 \%$ & OS \\
\hline Lee et $\mathrm{al}^{15}$ & Korea & 2004 & 35 & I-IV & GC & RT-PCR & - & Survival rates \\
\hline Illemann et al $^{16}$ & Denmark & 2014 & 244 & I-IV & CRC & $\mathrm{ICH}$ & Score $\geq 0$ & OS \\
\hline Minoo et $\mathrm{al}^{17}$ & USA & 2010 & 975 & - & CRC & $\mathrm{ICH}$ & Score $\geq 0$ & Survival rates \\
\hline Taniguchi et al $^{18}$ & Japan & 1998 & 102 & - & GC & $\mathrm{ICH}$ & Score $\geq 30 \%$ & OS \\
\hline Yang et al $^{19}$ & Australia & 2000 & 59 & - & CRC & $\mathrm{ICH}$ & Score $\geq 0$ & OS \\
\hline Zhang et $\mathrm{al}^{20}$ & People's Republic of China & 2006 & 105 & - & GC & $\mathrm{ICH}$ & Score $\geq 50 \%$ & Survival rates \\
\hline
\end{tabular}

Note: ${ }^{\text {aCut }}$ off of uPAR high expression.

Abbreviations: $\mathrm{N}$, number of patients; GC, gastric cancer; ICH, immunohistochemistry; OS, overall survival; CRC, colorectal cancer; TMA, tissue micro-arrays; DFS, disease-free survival; RT-PCR, reverse transcriptase-polymerase chain reaction; uPAR, urokinase plasminogen activator receptor. 
Study name Statistics for each study

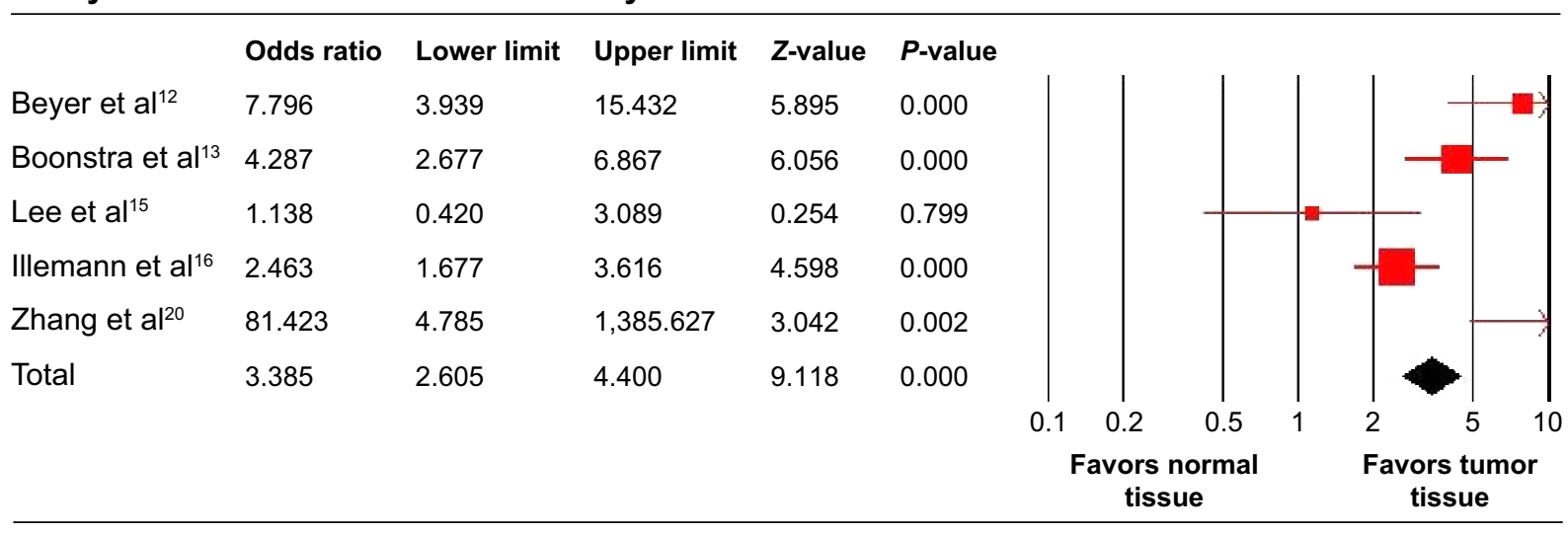

\section{Meta-analysis}

Figure 2 Forest plot: uPAR expression in tumor and normal tissues.

Abbreviations: uPAR, urokinase plasminogen activator receptor; $\mathrm{Cl}$, confidence interval.

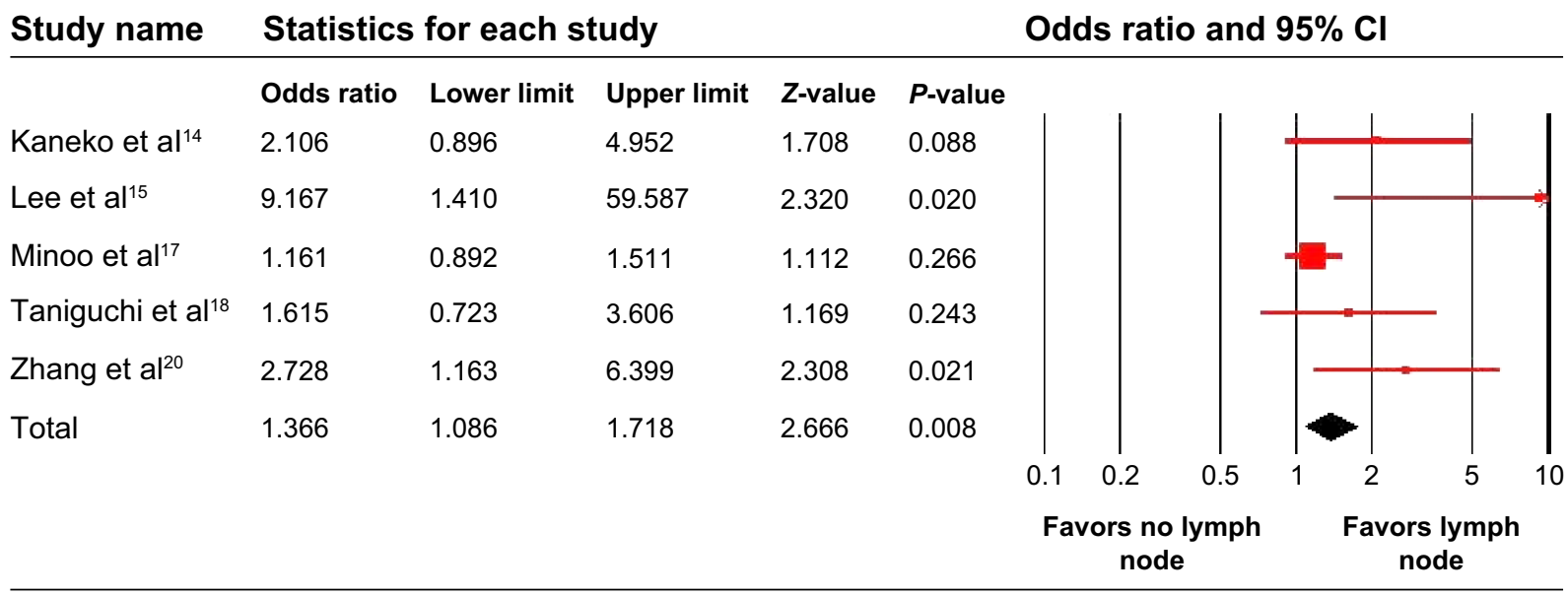

\section{Meta-analysis}

Figure 3 Forest plot: uPAR expression is associated with lymph node metastasis.

Abbreviations: uPAR, urokinase plasminogen activator receptor; $\mathrm{Cl}$, confidence interval.

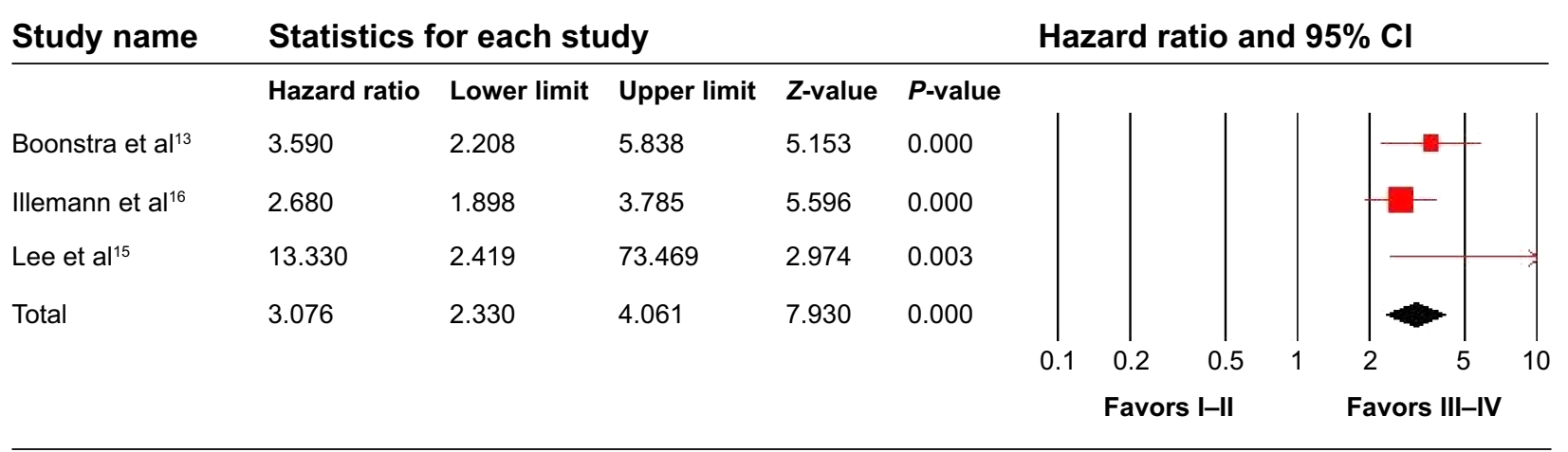

\section{Meta-analysis}

Figure 4 Forest plot: UPAR expression is associated with stage.

Abbreviations: uPAR, urokinase plasminogen activator receptor; $\mathrm{Cl}$, confidence interval. 


\begin{tabular}{|c|c|c|c|c|c|c|c|}
\hline Study name & Statistics $\mathbf{f}$ & for each st & tudy & & & Hazard ratio ar & Ind $95 \% \mathrm{Cl}$ \\
\hline & Hazard ratio & Lower limit & Upper limit & Z-value & $P$-value & & \\
\hline Alpízar-Alpízar et al111 & 2.160 & 1.128 & 4.134 & 2.325 & 0.020 & & - \\
\hline Boonstra et al ${ }^{13}$ & 1.925 & 1.159 & 3.198 & 2.529 & 0.011 & & \\
\hline Kaneko et al ${ }^{14}$ & 1.829 & 1.076 & 3.108 & 2.232 & 0.026 & & \\
\hline Illemann et al ${ }^{16}$ & 1.840 & 1.117 & 3.031 & 2.394 & 0.017 & & \\
\hline Taniguchi et al ${ }^{18}$ & 1.906 & 1.136 & 3.199 & 2.442 & 0.015 & & \\
\hline Yang et $\mathrm{al}^{19}$ & 2.030 & 1.305 & 3.157 & 3.142 & 0.002 & & \\
\hline \multirow[t]{3}{*}{ Total } & 1.937 & 1.570 & 2.390 & 6.173 & 0.000 & & \\
\hline & & & & & & $\begin{array}{llll}0.1 & 0.2 & 0.5 & 1\end{array}$ & $\begin{array}{llll}1 & 2 & 5 & 10\end{array}$ \\
\hline & & & & & & \multicolumn{2}{|c|}{$\begin{array}{cc}\begin{array}{c}\text { Favors low uPAR } \\
\text { expression }\end{array} & \begin{array}{c}\text { Favors high uPAR } \\
\text { expression }\end{array}\end{array}$} \\
\hline
\end{tabular}

\section{Meta-analysis}

Figure 5 Forest plot: uPAR expression is associated with OS.

Abbreviations: uPAR, urokinase plasminogen activator receptor; OS, overall survival; $\mathrm{Cl}$, confidence interval.

UPAR expression indicates local and distant metastasis of tumor cells. In contrast, uPAR expression did not significantly correlate with tumor size, depth of invasion, tumor differentiation, or serosal invasion.

\section{Effect of uPAR expression on OS of gastrointestinal cancer}

Of the ten studies included in our meta-analysis, six discussed the relationship between UPAR expression and OS of patients with GC and CRC. High uPAR expression correlated with poor $\mathrm{OS}(\mathrm{OR}=1.937 ; 95 \% \mathrm{CI}=1.570-2.930$; $P=0.000$ ) (Figure 5), indicating that $\mathrm{UPAR}$ is an independent prognostic factor in GC and CRC. No significant publication bias of OS was detected by the Funnel plot (Figure 6).

\section{Discussion}

To our knowledge, this is the first English meta-analysis to systematically determine the association between UPAR expression and survival of patients with $\mathrm{GC}$ and $\mathrm{CRC}$. The clinicopathologic features and prognostic significance of uPAR expression in GC and CRC are controversial. Although the majority of studies suggest that uPAR expression in GC and CRC is significantly associated with lymph node and distant metastasis, and poor prognosis, the conclusions of Kaneko et $\mathrm{al}^{14}$ and Minoo et $\mathrm{al}^{17}$ are not consistent. Therefore, to obtain a more precise assessment of the role of UPAR in $\mathrm{GC}$ and $\mathrm{CRC}$, we conducted a meta-analysis of ten eligible studies that included a total of 2,082 cases.

The expression and activation of uPA play an important role in tumorigenicity, and high endogenous levels of uPAR are associated with advanced cancers. ${ }^{21}$ The uPAR is a 55-60 kDa glycoprotein that belongs to the Ly-6 family. ${ }^{22}$
The gene encoding this receptor is located on chromosome $19 \mathrm{q} 13.2$, and is formed from seven exons separated by six introns. ${ }^{23}$ To date, uPARs have been identified on the surface of monocytes, granulocytes, fibroblasts, keratinocytes, vascular endothelial cells, and cancer cells. ${ }^{24}$ The binding of uPA to uPAR orchestrates different signaling molecules that mediate various biological responses, including proliferation, migration, invasion, angiogenesis, and metastasis. ${ }^{25}$ Several technical approaches affecting tumor growth and metastasis, such as antisense oligodeoxynucleotides, adenoviral vectors, monoclonal antibodies, toxins, natural and synthetic inhibitors, and linear and cyclic uPA-derived peptides targeting the UPA-uPAR system in cancer patients at gene and protein levels, have been explored. ${ }^{26-28}$ Tumor cell invasion is due to degradation of the extracellular matrix by proteases, and activation of the UPA-uPAR system initiates the destruction of various extracellular matrix proteins. Lymph node and

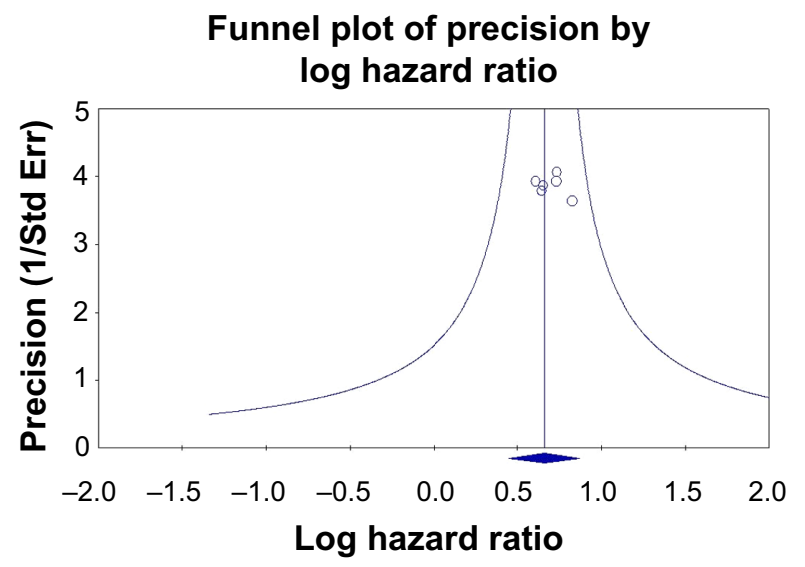

Figure 6 Funnel plot of the meta-analysis. Abbreviation: Std Err, standard error. 
distant metastases are the major prognostic factors in $\mathrm{GC}$ and CRC. In the meta-analysis presented here, we found that UPAR expression in GC and CRC tissues was markedly higher than in normal tissue. We also found that although UPAR expression was related to the status of lymph nodes and tumor node metastasis staging in an expanded sample, it was not significantly correlated with tumor size, depth of invasion, tumor differentiation, or serosal invasion. More importantly, higher expression of UPAR significantly correlated with poorer OS in GC and CRC, suggesting that UPAR may show promise as a prognostic indicator.

Some limitations need to be acknowledged in this metaanalysis. First, with 2,082 cases, the number of studies included was relatively small. Second, patient survival analyses were performed using only six studies, with detailed survival data reported in only a portion of these. We estimated survival information from $\mathrm{HR}$ and its $95 \% \mathrm{CI}$, which resulted in a certain degree of measurement bias. Third, it is clear that the two types of gastrointestinal cancer (GC and CRC) likely have different biological behaviors. Fourth, we were unable to assess the potential confounding variables in the individual studies, such as the method used for evaluation of uPAR expression and the choice of cutoff scores for positive staining. Fifth, some studies could not be included in our meta-analysis owing to the lack of detailed data or UPAR detected in blood samples. Sixth, we did not include other gastrointestinal adenocarcinomas in this study, for example, biliary/cholangio, esophageal, and pancreatic cancers. Hence, whether there is also abnormal expression of UPAR in these gastrointestinal adenocarcinomas is not clear, and this requires further study. In addition, most of the included studies were carried out in East Asia or Western countries, and the results may be different in other regions.

In conclusion, results of our meta-analysis indicate that UPAR expression is associated with the common clinicopathological parameters and outcomes of GC and CRC. Therefore, uPAR expression may serve as a novel disease marker in GC and CRC, as well as a therapeutic target.

\section{Acknowledgments}

This study was funded by Health Industry Research Program Management project in Gansu Province, People's Republic of China (GWGL2013-23). The funders had no role in study design, data collection and analysis, decision to publish, or preparation of the manuscript.

\section{Disclosure}

The authors report no conflicts of interest in this work.

\section{References}

1. Ong J, Salomon J, te Morsche RH, et al. Polymorphisms in the insulinlike growth factor axis are associated with gastrointestinal cancer. PLoS One. 2014;9(3):e90916.

2. Ferlay J, Shin HR, Bray F, Forman D, Mathers C, Parkin DM. Estimates of worldwide burden of cancer in 2008: GLOBOCAN 2008. Int $J$ Cancer. 2010;127(12):2893-2917.

3. Zhang T, Yu TT, Zhang DM, et al. Vasohibin-1 expression detected by immunohistochemistry correlates with prognosis in non-small cell lung cancer. Med Oncol. 2014;31(5):963.

4. Kenny HA, Leonhardt P, Ladanyi A, et al. Targeting the urokinase plasminogen activator receptor inhibits ovarian cancer metastasis. Clin Cancer Res. 2011;17(3):459-471.

5. Asuthkar S, Gondi CS, Nalla AK, Velpula KK, Gorantla B, Rao JS. Urokinase-type plasminogenactivatorreceptor (UPAR)-mediated regulation of WNT/ $\beta$-catenin signaling is enhanced in irradiated medulloblastoma cells. J Biol Chem. 2012;287(24):20576-20589.

6. Smith HW, Marshall CJ. Regulation of cell signalling by uPAR. Nat Rev Mol Cell Biol. 2010;11(1):23-36.

7. Thummarati P, Wijitburaphat S, Prasopthum A, et al. High level of urokinase plasminogen activator contributes to cholangiocarcinoma invasion and metastasis. World J Gastroenterol. 2012;18(3):244-250.

8. Urban P, Vuaroqueaux V, Labuhn M. Increased expression of urokinasetype plasminogenactivator mRNA determines adverse prognosis in ErbB2-positive primary breast cancer. J Clin Oncol. 2006;24(26): 4245-4253.

9. Mekkawy AH, Morris DL, Pourgholami MH. HAX1 augments cell proliferation, migration, adhesion, and invasion induced by urokinasetype plasminogen activator receptor. J Oncol. 2012;2012:950749.

10. Panic N, Leoncini E, de Belvis G, Ricciardi W, Boccia S. Evaluation of the endorsement of the preferred reporting items for systematic reviews and meta-analysis (PRISMA) statement on the quality of published systematic review and meta-analyses. PLoS One. 2013;8(12):e83138.

11. Alpízar-Alpízar W, Christensen IJ, Santoni-Rugiu E, et al. Urokinase plasminogen activator receptor on invasive cancer cells: a prognostic factor in distal gastric adenocarcinoma. Int J Cancer. 2012;131(4): E329-E336.

12. Beyer BC, Heiss MM, Simon EH, et al. Urokinase system expression in gastriccarcinoma: prognostic impact in an independent patient series and first evidence of predictive value in preoperative biopsy and intestinal metaplasia specimens. Cancer. 2006;106(5):1026-1035.

13. Boonstra MC, Verbeek FP, Mazar AP, et al. Expression of uPAR in tumor-associated stromal cells is associated with colorectal cancer patient prognosis: a TMA study. BMC Cancer. 2014;14:269.

14. Kaneko T, Konno H, Baba M, Tanaka T, Nakamura S. Urokinase-type plasminogen activator expression correlates with tumor angiogenesis and poor outcome in gastric cancer. Cancer Sci. 2003;94(1):43-49.

15. Lee KH, Bae SH, Lee JL, et al. Relationship between urokinase-type plasminogen receptor, interleukin-8 gene expression and clinicopathological features in gastric cancer. Oncology. 2004;66(3):210-217.

16. Illemann M, Laerum OD, Hasselby JP, et al. Danish Study Group on Early Detection of Colorectal Cancer. Urokinase-type plasminogen activator receptor (UPAR) on tumor-associated macrophages is a marker of poor prognosis in colorectal cancer. Cancer Med. 2014;3(4):855-864.

17. Minoo P, Baker K, Baumhoer D, Terracciano L, Lugli A, Zlobec I. Urokinase-type plasminogen activator is a marker of aggressive phenotype and an independent prognostic factor in mismatch repair-proficient colorectal cancer. Hum Pathol. 2010;41(1):70-78.

18. Taniguchi K, Yonemura Y, Nojima N, et al. The relation between the growth patterns of gastriccarcinoma and the expression of hepatocyte growth factor receptor (c-met), autocrine motility factor receptor, and urokinase-type plasminogen activator receptor. Cancer. 1998;82(11): 2112-2122.

19. Yang JL, Seetoo DQ, Wang Y, et al. Urokinase-type plasminogen activator and its receptor in colorectal cancer: independent prognostic factors of metastasis and cancer-specific survival and potential therapeutic targets. Int J Cancer. 2000;89(5):431-439. 
20. Zhang L, Zhao ZS, Ru GQ, Ma J. Correlative studies on uPA mRNA and UPAR mRNA expression with vascular endothelial growth factor, microvessel density, progression and survival time of patients with gastric cancer. World J Gastroenterol. 2006;12(25):3970-3976.

21. Kargiotis O, Chetty C, Gogineni V, et al. uPA/uPAR down regulation inhibits radiation-induced migration, invasion and angiogenesis in IOMM-Lee meningioma cells and decreases tumor growth in vivo. Int J Oncol. 2008;33(5):937-947.

22. Li Y, Shen Y, Miao Y, Luan Y, Sun B, Qiu X. Co-expression of uPAR and CXCR4 promotes tumor growth and metastasis in small cell lung cancer. Int J Clin Exp Pathol. 2014;7(7):3771-3780.

23. Thielemann A, Baszczuk A, Kopczyński P, Kopczyński Z. High concentration of urokinase-type plasminogen activator receptor in the serum of women with primary breast cancer. Contemp Oncol (Pozn). 2013;17(5):440-445.

24. Hasanuzzaman M, Kutner R, Agha-Mohammadi S, Reiser J, Sehgal I. A doxycycline-inducible urokinase receptor ( $\mathrm{UPAR}$ ) upregulates UPAR activities including resistance to anoikis in human prostate cancer cell lines. Mol Cancer. 2007;6:34.
25. Pulukuri SM, Gorantla B, Dasari VR, Gondi CS, Rao JS. Epigenetic upregulation of urokinase plasminogen activator promotes the tropism of mesenchymal stem cells for tumor cells. Mol Cancer Res. 2010;8(8): 1074-1083.

26. Kondraganti S, Gondi CS, McCutcheon I, et al. RNAi-mediated downregulation of urokinase plasminogen activator and its receptor in human meningioma cells inhibits tumor invasion and growth. Int J Oncol. 2006;28(6):1353-1360.

27. Yin S, Lockett J, Meng Y, et al. Maspin retards cell detachment via a novel interaction with the urokinase-type plasminogen activator/ urokinase-type plasminogen activator receptor system. Cancer Res. 2006; 66(8):4173-4181.

28. Sorio C, Mafficini A, Furlan F, et al. Elevated urinary levels of urokinase-type plasminogen activator receptor (UPAR) in pancreatic ductal adenocarcinoma identify a clinically high-risk group. $B M C$ Cancer. 2011;11:448.
OncoTargets and Therapy

\section{Publish your work in this journal}

OncoTargets and Therapy is an international, peer-reviewed, open access journal focusing on the pathological basis of all cancers, potential targets for therapy and treatment protocols employed to improve the management of cancer patients. The journal also focuses on the impact of management programs and new therapeutic agents and protocols on

\section{Dovepress}

patient perspectives such as quality of life, adherence and satisfaction. The manuscript management system is completely online and includes a very quick and fair peer-review system, which is all easy to use. Visit http://www.dovepress.com/testimonials.php to read real quotes from published authors. 